\title{
Alveolar antioxidant status in patients with acute respiratory distress syndrome
}

\author{
R. Schmidt, T. Luboeinski, P. Markart, C. Ruppert, C. Daum, F. Grimminger, W. Seeger, A. Günther
}

Alveolar antioxidant status in patients with acute respiratory distress syndrome. R. Schmidt, T. Luboeinski, P. Markart, C. Ruppert, C. Daum, F. Grimminger, W. Seeger, A. Günther. (C)ERS Journals Ltd 2004.

ABSTRACT: In the acutely inflamed lung, oxidant stress occurs within the alveolar compartment. Under these conditions, the regulation of low molecular weight antioxidants in the epithelial lining fluid is poorly understood. Therefore, antioxidant levels were measured in the bronchoalveolar lavage fluid (BALF) of patients with acute respiratory distress syndrome $(A R D S ; n=40)$ and in healthy volunteers $(n=20)$.

Reduced glutathione (GSH), oxidised glutathione (GSSG; enzymatic assay), retinol (vitamin A), $\alpha$-tocopherol (vitamin E), ascorbic acid (vitamin C), uric acid (all by HPLC), plasmalogens (1-alkenyl-2-acyl phospholipids), polyunsaturated fatty acids (PUFA; both by gas-liquid chromatography), and $\mathbf{F}_{2}$-isoprostanes (ELISA) were quantified. All values are expressed as concentrations in cell-depleted BALF.

GSSG (ARDS: $0.13 \pm 0.02 \mu \mathrm{M}$; control: $0.03 \pm 0.01 \mu \mathrm{M}$; mean \pm SEM) and $\mathrm{F}_{2-}$ isoprostanes (ARDS: $78 \pm 10 \mathrm{pM}$; control: $26 \pm 5 \mathrm{pM}$ ) were increased in ARDS, thus indicating oxidant stress. GSH levels in patients did not change significantly, whereas concentrations of vitamins $A$ and $C$, vitamin $E$ (ARDS: $77 \pm 15 \mathrm{nM}$; control: $26 \pm 3 \mathrm{nM}$ ) and uric acid (ARDS: $11.8 \pm 2.2 \mu \mathrm{M}$; control: $0.7 \pm 0.0 \mu \mathrm{M})$ were significantly elevated in ARDS. PUFA of total lipids, which may act as sacrificial antioxidants, increased by a factor of $\sim 3$ in patients, but plasmalogens showed a significant decrease.

In conclusion, low molecular weight antioxidants are elevated in the alveolar compartment of patients with acute respiratory distress syndrome. Further research is warranted to elucidate the molecular mechanisms underlying this finding.

Eur Respir J 2004; 24: 994-999.
Dept of Internal Medicine, Justus-LiebigUniversity, Giessen, Germany.

Correspondence: R. Schmidt

Dept of Internal Medicine

Justus-Liebig-University

Friedrichstrasse 24

D-35392 Giessen, Germany.

Fax: 496419942429

E-mail: reinhold.schmidt@innere.med. uni-giessen.de

Keywords: Acute lung injury

antioxidants

bronchoalveolar lavage

oxidative stress

Received: October 282003

Accepted after revision: August 162004

This study was supported by the Deutsche Forschungsgemeinschaft (SCHM 1524/2-1), Bonn, Germany.
The alveolar compartment is permanently exposed to reactive oxygen (ROS) and nitrogen species (RNS) derived from inhaled air pollutants. The antioxidant defence system of the epithelial lining fluid consists of several low molecular weight compounds, such as reduced glutathione (GSH), ascorbic acid (vitamin $\mathrm{C}$ ) and uric acid, lipophilic antioxidants, such as $\alpha$-tocopherol (vitamin E), retinol (vitamin A) and plasmalogens (1-alkenyl-phospholipids), and antioxidant enzymes, with superoxide dismutases, catalase, and the glutathione peroxidases representing notable examples [1, 2]. In the normal lung, complex and coordinated interactions of all antioxidant compounds provide protection of the distal lung structures from the damaging effects of oxidative attack.

Inflammation of the lung may result in activation of macrophages and neutrophils, and release of free radicals due to respiratory burst. In addition, commonly used high inspiratory concentrations of oxygen may contribute to generation of free radicals [3]. Accordingly, a large number of authors have provided evidence that oxidative-degradation products are elevated in acute respiratory distress syndrome (ARDS) patients, both in bronchoalveolar lavage fluid (BALF) and in exhaled breath condensate [4-6]. This imbalance between newly generated oxidative compounds and the local antioxidative systems may well contribute to lung injury, resulting in increased capillary leakage [7], altered surfactant metabolism [2, 8, 9] and diminished surfactant function [10]. This may further enhance alveolar oedema and collapse, frequently encountered in ARDS and acute lung injury (ALI).

Since ARDS/ALI are associated with elevated levels of reactive oxidants in BALF, and based on findings that blood antioxidant concentrations are reduced [11], it has long been hypothesised that alveolar antioxidants may be decreased in BALF of these patients [12]. In view of the low molecular weight antioxidant compounds, data are conflicting and scarce. It has, for example, been suggested that GSH is reduced in BALF of ARDS patients [5, 13]. Such analysis of single compounds may be complicated by the overall low levels of these substances in BALF, due to the 100-200-fold dilution of epithelial lining fluid (ELF) during the lavage procedure. Thus, highly sensitive and selective analytical procedures seem to represent a prerequisite for such analysis [1].

In light of these considerations, the present study was undertaken to carefully quantify single antioxidant compounds in BALF from 40 patients with ARDS. A total of 20 healthy volunteers served as controls. A significant increase was found for the majority of single antioxidant parameters investigated, with the exception of GSH and plasmalogens. It is concluded that increased oxidant burden in the distal lung regions of ARDS patients is followed or accompanied by an increase in antioxidant compounds. 


\section{Methods}

\section{Patient population}

The study was conducted at the Dept of Internal Medicine, Justus-Liebig-University, Giessen, Germany, and included 40 patients fulfilling ARDS criteria, according to the definition of the American European Consensus Conference of ARDS [14]. In detail, patients with ARDS had a history of acutely developing dyspnoea, arterial oxygen tension $\left(\mathrm{Pa}, \mathrm{O}_{2}\right) /$ inspiratory oxygen fraction $\left(F \mathrm{I}, \mathrm{O}_{2}\right)$ values of $<200 \mathrm{mmHg}(1 \mathrm{kPa}=$ $0.133 \mathrm{mmHg}$ ), pulmonary infiltrates, and pulmonary artery wedge pressures (PAWP) $<18 \mathrm{mmHg}$ or missing signs of left heart failure in echocardiography. Underlying reasons for the development of ARDS were pneumonia ( $n=31$; primary ARDS), sepsis syndrome ( $\mathrm{n}=8$; secondary ARDS), and pancreatitis ( $\mathrm{n}=1$; secondary ARDS).

Exclusion criteria for all patients were PAWP $>18 \mathrm{mmHg}$, lung contusion, pre-existing pulmonary diseases (fibrosis, chronic obstructive pulmonary disease), malignant underlying diseases, pregnancy and additional investigational drugs.

All patients received a standardised total parenteral nutrition regimen, including amino acids and trace elements (Aminomix 2®); Fresenius Kabi, Bad Homburg, Germany), lipids (Intralipid 20®; Baxter, Unterschleissheim, Germany), and a multivitamin preparation (Cernevit $\AA$-12; Baxter; 1 vial $\cdot$ day $\left.^{-1}\right)$. Cernevit- 12 contains, among others, $10.2 \mathrm{mg}$ $\alpha$-tocopherol, $1.93 \mathrm{mg}$ retinol palmitate and $125 \mathrm{mg}$ ascorbic acid. All patients were mechanically ventilated, and fibreoptic bronchoscopy and bronchoalveolar lavage (BAL) were performed for diagnostic purposes directly after the onset of mechanical ventilation. A total of 20 healthy volunteers were lavaged in a similar manner. The protocol was approved by the local ethics committee of the Justus-Liebig-University. Each patient or their closest relatives provided informed consent. Demographic and basic clinical data are given in table 1 . The mean arterial oxygenation index $\left(P \mathrm{a}, \mathrm{O}_{2} / F \mathrm{I}, \mathrm{O}_{2}\right)$ was $143 \mathrm{mmHg}$ in ARDS (all patients), $134 \mathrm{mmHg}$ in patients with primary ARDS and $170 \mathrm{mmHg}$ in patients with secondary ARDS. There was no significant difference in 28-day mortality between primary and secondary ARDS (table 1). The recovery of the BALF was reduced by $\sim 20 \%$ in ARDS compared with healthy controls (table 1).

Bronchoalveolar lavage. Flexible fibreoptic bronchoscopy was performed in all patients and controls by one physician in a standardised manner, as previously described [15]. One segment of the lingula or the right middle lobe was lavaged with a total volume of $140 \mathrm{~mL}$ of sterile normal saline in seven equal aliquots. The recovered BALF was pooled, filtered through sterile gauze, and immediately centrifuged $(300 \times g$, $10 \mathrm{~min}, 4^{\circ} \mathrm{C}$ ) to remove cells and membranous debris. Aliquots of BALF for antioxidant analysis were supplied with $0.01 \%$ butylated hydroxytoluene (BHT), frozen in liquid nitrogen and stored at $-80^{\circ} \mathrm{C}$. Staining and counting of the pelleted cells were performed according to routine standards. In keeping with the recommendations of the European Respiratory Society (ERS) Task Force [1, 16, 17], measurements of noncellular constituents were reported in concentrations per $\mathrm{mL}$ of recovered BALF.

Lipid and protein analysis. Lipids were extracted from BALF with chloroform/methanol, and phospholipid content was determined by spectrophotometric measurement, as previously described [15]. Total proteins were analysed using a commercial assay (Bicinchoninic acid protein quantitation assay; Pierce, Bonn, Germany).

\section{Antioxidant analysis}

Reduced and oxidised glutathione. Total glutathione and oxidised glutathione (GSSG) were determined by enzymatic recycling assay originally described by TIETZE [18], adapted for microtitre plates. GSSG was measured after masking of GSH with $N$-ethylmaleimide (NEM) and separation of GSH-NEM using solid-phase extraction.

Vitamin $E$ and vitamin $A$. The hydrophobic vitamins $\alpha$ tocopherol (vitamin E) and retinol (vitamin A) were simultaneously analysed by HPLC and diode array detection, according to the method of CATIGNANI and BIERI [19]. Retinol and $\alpha$-tocopherol were simultaneously detected at $324 \mathrm{~nm}$ and $292 \mathrm{~nm}$, respectively. Peak purity was checked using the corresponding ultraviolet spectra. Analytes were quantified by means of standard curves for each vitamin, after correction for internal standard (retinol acetate) variability.

Vitamin $C$ and uric acid. Vitamin C (ascorbic acid (AA)) and uric acid (UA) were measured using HPLC, according to the method of IRIYAMA et al. [20]. Detection was accomplished using a HP 1049A electrochemical detector (Agilent, Waldbronn, Germany), equipped with a $\mathrm{Ag} / \mathrm{AgCl}$ working electrode and set at $+800 \mathrm{mV}$.

Table 1.-Demographic, clinical and routine laboratory data of the study population

\begin{tabular}{|c|c|c|c|c|}
\hline & Control & ARDS all patients & Primary ARDS & Secondary ARDS \\
\hline Subjects $n$ & 20 & 40 & 31 & 9 \\
\hline Age yrs & $28.1 \pm 1.3$ & $54.3 \pm 2.3 * * *$ & $55.9 \pm 2.8^{* * *}$ & $48.9 \pm 3.3 * * *$ \\
\hline Sex F/M & $10 / 10$ & $17 / 23$ & $13 / 18$ & $4 / 5$ \\
\hline $\mathrm{Pa}_{2} \mathrm{O}_{2} / F \mathrm{I}, \mathrm{O}_{2} \mathrm{mmHg}$ & $455.1 \pm 15.1$ & $143.0 \pm 9.0 * * *$ & $134.0 \pm 9.1 * * *$ & $170.2 \pm 22.2 * * *$ \\
\hline Patients alive on day 28 & & $30(75.0)$ & $23(74.2)$ & $7(77.8)$ \\
\hline BALF recovery $\%$ & $79.7 \pm 2.2$ & $58.8 \pm 2.5^{* * *}$ & $57.1 \pm 2.6^{* * *}$ & $64.1 \pm 6.1^{*}$ \\
\hline Neutrophils $\%$ & $1.1 \pm 0.2$ & $55.2 \pm 4.3^{* * *}$ & $54.0 \pm 5.6^{* * *}$ & $59.0 \pm 4.7 * * *$ \\
\hline Lymphocytes \% & $4.4 \pm 0.7$ & $8.8 \pm 2.5$ & $10.3 \pm 3.3$ & $4.2 \pm 1.1$ \\
\hline Macrophages $\%$ & $94.5 \pm 0.6$ & $36.0 \pm 3.5^{* * *}$ & $35.7 \pm 4.5^{* * *}$ & $36.8 \pm 4.9 * * *$ \\
\hline $\mathrm{PL} \mu \mathrm{g} \cdot \mathrm{ml}^{-1}$ & $31.8 \pm 3.7$ & $27.2 \pm 2.8$ & $25.4 \pm 3.3$ & $33.2 \pm 5.4$ \\
\hline Protein $\mathrm{mg} \cdot \mathrm{ml}^{-1}$ & $0.07 \pm 0.00$ & $1.04 \pm 0.12^{* * *}$ & $1.09 \pm 0.21^{* * *}$ & $0.94 \pm 0.32 * * *$ \\
\hline PPQ & $0.460 \pm 0.028$ & $0.042 \pm 0.009^{* * *}$ & $0.035 \pm 0.007^{* * *}$ & $0.063 \pm 0.029^{* * *}$ \\
\hline
\end{tabular}

Data are presented as $\mathrm{n}$, mean \pm SEM and $\mathrm{n}(\%)$. Acute respiratory distress syndrome (ARDS) patients were further divided into primary and secondary ARDS. F: female; M: male; $P \mathrm{a}, \mathrm{O}_{2}$ : arterial oxygen tension; $\mathrm{FI}, \mathrm{O}_{2}$ : inspiratory oxygen fraction; BALF: bronchoalveolar lavage fluid; PL: total phospholipids in BALF; protein: total protein in BALF; PPQ: phospholipid-protein ratio. ${ }^{*}: \mathrm{p}<0.05 ; * * *: \mathrm{p}<0.001 .1 \mathrm{kPa}=0.133 \mathrm{mmHg}$. 
Polyunsaturated fatty acids and plasmalogens. Total lipids were isolated as described previously, and fatty acids and plasmalogens were determined simultaneously using gas chromatography as previously described [21]. The following fatty acids were used for calculation of polyunsaturated fatty acids (PUFA): 18:2, $\gamma-18: 3,18: 3,20: 2,20: 3(3), 20: 3(6), 20: 3(9)$, $20: 4,20: 5,22: 3,22: 4,22: 5$, and 22:6. The ratio ((weight of dimethylacetals (DMA)/weight of fatty acid methyl esters $($ FAME $)) \times 2$ ) of the detected DMA to FAME indicated the relative amount of plasmalogens within the phospholipid fraction. Due to the lack of BHT-supplemented BALF material, plasmalogens and PUFA were only measured in 14 controls and 31 ARDS patients.

Analysis of $F_{2}$-isoprostanes. $\mathrm{F}_{2}$-isoprostanes were quantified by means of an ELISA (Cayman Chemical, Ann Arbor, MI, USA). In brief, samples (500 $\mu \mathrm{L}$ BALF) were purified and concentrated by solid-phase extraction $(3 \mathrm{~mL}$ Chromabond $\mathrm{C} 18 \mathrm{ec}$ cartridges; Macherey Nagel, Düren, Germany), and $\mathrm{F}_{2^{-}}$ isoprostanes were eluted and subjected to ELISA, as detailed in the supplier's manual.

\section{Statistical analysis}

The results were expressed as mean \pm SEM for each group. First, statistical analysis of differences between patients and controls and between patients with primary and secondary ARDS was performed by testing principle significance diversity (Kruskal-Wallis H-test), followed by comparison with a nonparametric test (Mann-Whitney U-Test). Values significantly different from control are indicated as $\mathrm{p}<0.05$, $\mathrm{p}<0.01$, and $\mathrm{p}<0.001$.

\section{Results}

As anticipated, ARDS patients had markedly increased neutrophil and decreased macrophage counts in the BALF cell differential. Total BALF protein was highly elevated in ARDS, whilst total phospholipids did not differ significantly between patients and controls (table 1).

In BALF from healthy controls, GSH was the most abundant antioxidant molecule $(\sim 1.6 \mu \mathrm{M})$, followed by AA $(\sim 0.5 \mu \mathrm{M})$ and UA $(\sim 0.7 \mu \mathrm{M})$. The concentrations of the lipophilic antioxidants $\alpha$-tocopherol $(\sim 26 \mathrm{nM})$ and retinol $(\sim 5 \mathrm{nM})$ were relatively low (table 2$)$.

Patients with ARDS $(0.13 \mu \mathrm{M} ; \mathrm{p}<0.001)$ showed higher concentrations of GSSG compared with controls $(0.03 \mu \mathrm{M}$; table 2). Accordingly, $\mathrm{F}_{2}$-isoprostane levels, as markers for lipid peroxidation, were significantly elevated in ARDS, thus indicating oxidant stress (table 2). The present authors were not able to detect considerable amounts of malondialdehyde both in controls and in patients with the currently used technique (HPLC with fluorescence detection), suggesting very low concentrations of this lipid degradation product in BALF.

The concentration of GSH was not different in ARDS as compared with controls (table 2). The analysis of AA by HPLC revealed an approximately four-fold elevation in ARDS (2.4 $\mu \mathrm{M} ; \mathrm{p}<0.05$; table 2). Similarly, the concentration of UA was elevated in ARDS $(11.8 \mu \mathrm{M} ; \mathrm{p}<0.001)$ compared with controls (table 2). The analysis of $\alpha$-tocopherol (vitamin E) revealed a significant increase in ARDS ( $77 \mathrm{nM}$; table 2). The concentrations of retinol (vitamin A) were approximately seven-fold elevated in ARDS $(\sim 32 \mathrm{nM} ; \mathrm{p}<0.001)$ compared with controls (table 2).

In contrast to all other antioxidants investigated, plasmalogens were significantly decreased in ARDS, and this was true for both the absolute and relative (compared with total phospholipids) concentration (tables 2 and 3). The absolute and the relative content of PUFA, which may act as sacrificial agents under oxidant stress, were 2 -3-fold elevated in ARDS compared with controls (tables 2 and 3 ).

In an attempt to compensate for the dilution variability during BAL procedure, phospholipid coefficients were calculated for all measured parameters (table 3). When using the phospholipid concentration as a denominator, nearly the same results as described previously were obtained. In contrast, when performing urea correction (urea concentration in blood/urea concentration in BALF), no significant difference in GSSG and $\mathrm{F}_{2}$-isoprostane levels were observed (data not given in detail). Urea-corrected GSH was significantly decreased in ARDS $(71.0 \mu \mathrm{M}$ versus $216.5 \mu \mathrm{M}$ in controls; $\mathrm{p}<0.001)$, UA concentrations were still significantly elevated (ARDS: $342 \mu \mathrm{M}$ versus $100 \mu \mathrm{M}$ in controls; $\mathrm{p}<0.001$ ), retinol values were approximately threefold elevated in ARDS, whilst all other antioxidant compounds showed only minor differences compared with controls (data not given in detail).

Patients with ARDS were further divided into primary $\operatorname{ARDS}(n=31)$ and secondary ARDS $(n=9)$. Only minor differences were observed in GSH levels in primary ARDS $(1.5 \pm 0.4 \mu \mathrm{M})$ and in secondary ARDS $(1.4 \pm 0.3 \mu \mathrm{M})$. In contrast, the absolute concentrations of AA and UA were lower in primary ARDS compared with secondary ARDS (table 2), but these differences were not significant. Additionally, when using the total phospholipid concentration as a denominator, only minor differences between primary and secondary ARDS could be detected (table 3). The concentrations of plasmalogens and PUFA did not change between primary and secondary ARDS.

Table 2. - Absolute concentration of bronchoalveolar lavage fluid (BALF) oxidation markers and antioxidants

\begin{tabular}{|c|c|c|c|c|}
\hline & Control & ARDS all patients & Primary ARDS & Secondary ARDS \\
\hline GSSG $\mu \mathrm{M}$ & $0.032 \pm 0.016$ & $0.125 \pm 0.024 * * *$ & $0.120 \pm 0.031 * *$ & $0.140 \pm 0.040 * *$ \\
\hline $\mathrm{F}_{2}$-isoprostanes $\mathrm{pM}$ & $26.3 \pm 5.2$ & $77.9 \pm 10.2^{* * *}$ & $77.3 \pm 12.7 * *$ & $79.8 \pm 15.5^{* *}$ \\
\hline $\mathrm{GSH} \mu \mathrm{M}$ & $1.56 \pm 0.20$ & $1.51 \pm 0.34$ & $1.55 \pm 0.44$ & $1.36 \pm 0.28$ \\
\hline Ascorbic acid $\mu \mathrm{M}$ & $0.51 \pm 0.05$ & $2.36 \pm 0.60^{*}$ & $2.25 \pm 0.72 *$ & $2.73 \pm 0.98 * *$ \\
\hline Uric acid $\mu \mathrm{M}$ & $0.70 \pm 0.04$ & $11.80 \pm 2.22 * * *$ & $10.20 \pm 1.65^{* * *}$ & $17.16 \pm 4.17 * * *$ \\
\hline$\alpha$-Tocopherol nM & $26.4 \pm 3.09$ & $77.3 \pm 15.1^{* *}$ & $84.6 \pm 18.8^{* *}$ & $52.1 \pm 15.3$ \\
\hline Retinol nM & $4.8 \pm 1.0$ & $32.3 \pm 9.5^{* * *}$ & $34.8 \pm 12.1 * * *$ & $23.8 \pm 5.7 * * *$ \\
\hline Plasmalogens $\mathrm{ng} \cdot \mathrm{mL}^{-1}$ & $367.9 \pm 50.3$ & $206.5 \pm 29.1^{* * *}$ & $191.9 \pm 42.3 *$ & $216.9 \pm 40.8^{*}$ \\
\hline PUFA $\mu \mathrm{g} \cdot \mathrm{mL}^{-1}$ & $2.38 \pm 0.28$ & $6.71 \pm 0.95^{* * *}$ & $6.32 \pm 1.29 *$ & $6.99 \pm 1.37 *$ \\
\hline
\end{tabular}

Data are presented as mean \pm SEM. The absolute concentrations of oxidised glutathione (GSSG), $\mathrm{F}_{2}$-isoprostanes, reduced glutathione (GSH), vitamins C (ascorbic acid), E ( $\alpha$-tocopherol) and A (retinol), uric acid, plasmalogens, and polyunsaturated fatty acids (PUFA) are given. Acute respiratory distress syndrome (ARDS) patients were further divided into primary and secondary ARDS. *: $\mathrm{p}<0.05 ; * *: \mathrm{p}<0.01 ; * * *: \mathrm{p}<0.001$ compared with controls. 
Table 3. - Relative concentration of bronchoalveolar lavage fluid (BALF) oxidation markers and antioxidants

\begin{tabular}{|c|c|c|c|c|}
\hline & Control & ARDS all patients & Primary ARDS & Secondary ARDS \\
\hline GSSG/PL M/M & $0.001 \pm 0.001$ & $0.006 \pm 0.002 * * *$ & $0.006 \pm 0.002 * *$ & $0.005 \pm 0.002 * *$ \\
\hline $\mathrm{F}_{2}$-isoprostanes/PL $\mathrm{M} / \mathrm{M} \times 10^{6}$ & $0.79 \pm 0.18$ & $3.36 \pm 0.62 * * *$ & $3.59 \pm 0.77^{* *}$ & $2.66 \pm 0.98^{* *}$ \\
\hline GSH/PL M/M & $0.05 \pm 0.01$ & $0.11 \pm 0.04$ & $0.13 \pm 0.05$ & $0.05 \pm 0.02$ \\
\hline Ascorbic acid/PL M/M & $0.013 \pm 0.001$ & $0.096 \pm 0.027^{* *}$ & $0.105 \pm 0.034 * *$ & $0.065 \pm 0.020^{* *}$ \\
\hline Uric acid/PL M/M & $0.020 \pm 0.002$ & $0.384 \pm 0.067 * * *$ & $0.393 \pm 0.079 * * *$ & $0.352 \pm 0.128 * * *$ \\
\hline$\alpha$-Tocopherol/PL $\mathrm{M} / \mathrm{M} \times 10^{3}$ & $0.65 \pm 0.06$ & $2.04 \pm 0.23 * * *$ & $2.28 \pm 0.26^{* * *}$ & $1.22 \pm 0.34$ \\
\hline Retinol/PL M/M $\times 10^{3}$ & $0.14 \pm 0.04$ & $0.75 \pm 0.13^{* * *}$ & $0.81 \pm 0.17 * * *$ & $0.58 \pm 0.15^{* * *}$ \\
\hline Plasmalogens/PL \% & $1.07 \pm 0.04$ & $0.68 \pm 0.05^{* * *}$ & $0.63 \pm 0.06^{* * *}$ & $0.72 \pm 0.07 * * *$ \\
\hline PUFA/total FA \% & $7.19 \pm 0.29$ & $20.70 \pm 1.39 * * *$ & $20.06 \pm 1.96^{* * *}$ & $21.09 \pm 1.94 * * *$ \\
\hline
\end{tabular}

Data are presented as mean \pm SEM. The relative (compared with total BALF phospholipids (PL)) concentrations of oxidised glutathione (GSSG), $\mathrm{F}_{2}$-isoprostanes, reduced glutathione (GSH), vitamins C (ascorbic acid), E ( $\alpha$-tocopherol) and A (retinol), and uric acid are given. Plasmalogens and polyunsaturated fatty acids (PUFA) are given as percent (weight/weight) of total phospholipids or total fatty acids (FA) in BALF. Acute respiratory distress syndrome (ARDS) patients were further divided into primary and secondary ARDS. ${ }^{* *}$ : $\mathrm{p}<0.01 ; * * *$ : $\mathrm{p}<0.001$ compared with controls.

The results of correlational analysis with the data presented here and markers for severity of the disease $\left(\mathrm{Pa}, \mathrm{O}_{2} / \mathrm{FI}, \mathrm{O}_{2}\right)$ and clinical outcome (28-day mortality) revealed that no significant correlation could be detected when comparing antioxidant and oxidative degradation product levels with $\mathrm{Pa}, \mathrm{O}_{2} /$ $F \mathrm{I}, \mathrm{O}_{2}$ values. Furthermore, no significant difference could be observed between 28-day survivors and nonsurvivors, in view of the addressed markers.

\section{Discussion}

The present study sought to investigate the regulation of low molecular weight antioxidant molecules in ARDS. In contrast to other diseases with underlying inflammatory events, such as asthma [22] and bronchiolitis obliterans syndrome in lung transplantation [23], less is known about the regulation and distribution of alveolar low molecular weight antioxidants in these entities. Recent investigations in ARDS mainly focused on glutathione levels and BALF concentrations of some antioxidant enzymes and proteins. In the present study, GSH, the hydrophilic antioxidants AA and $\mathrm{UA}$, and the membrane-associated antioxidants plasmalogens, vitamins $\mathrm{E}$ and $\mathrm{A}$ were identified as the predominant low molecular weight antioxidants in BALF of healthy individuals. Only very small amounts of oxidation products, such as GSSG and $F_{2}$-isoprostanes, were detected.

Under conditions of ARDS, markers of oxidant stress (GSSG and $\mathrm{F}_{2}$-isoprostanes) were several-fold elevated, consistent with previous investigations $[5,6]$. The relatively low concentration of $\mathrm{F}_{2}$-isoprostanes in BALF suggests that generation of these oxidised lipids is limited under these conditions or that they are rapidly cleared from alveolar space, either by metabolic pathways or by transfer into the blood compartment.

Upregulation of the majority of the investigated antioxidant compounds was consistently observed. The most abundant alveolar antioxidant GSH, however, showed no significant change compared with controls. This is in contrast to previous reports, in which significant reductions in GSH levels were found in ARDS [5, 13]. The main reason for this discrepancy may be related to the use of a urea coefficient for correction of BAL variability in these studies. As has been repeatedly discussed, BAL/blood urea quotient-based correction of the concentration of BALF compounds is prone to pitfalls, which may arise from the rapid diffusion of urea, especially through the leaky barrier in inflammatory lung diseases. Also, the existing oedema fluid, enriched with urea, may lead to falsely too low values and to large interpatient variation [24]. In line with such reasoning, similar changes in the concentration of GSH were observed, as compared with the previous studies, when applying the urea-based correction method. In the current study, the guidelines of the ERS Task Force Report were followed [1, 16, 17], and all values were reported as concentrations per $\mathrm{mL}$ of BALF. Additionally, as suggested by the ERS Task Force, the recovery of instilled lavage fluid was reported, and the BALF phospholipid concentration was used as a denominator.

The hydrophilic antioxidants (AA and UA) appeared to be more upregulated compared with the lipophilic antioxidants (vitamins A and E). PUFA, which may act as sacrificial antioxidants, were also markedly elevated in the current patient groups.

In contrast to all other antioxidants assessed here, plasmalogens, which are believed to represent integral components of pulmonary surfactant [25] and powerful antioxidants [26], were decreased in both patient groups, in view of their absolute as well as their relative content (compared with total phospholipids). On the one hand, this may suggest increased degradation and/or impaired synthesis/ secretion on the other hand. Interestingly, this clearly differs from vitamins $\mathrm{A}$ and $\mathrm{E}$, which were found here to be clearly upregulated and are also actively secreted with pulmonary surfactant by type II cells [25].

In the current investigation, a persistent oxidative stress was observed in distal lung structures in ARDS patients. Despite the fact that alveolar antioxidants are increased, an excess of oxidative forces persists, ultimately leading to oxidant/antioxidant imbalance. As a result, various forms of molecular damage occur in response to the formation of ROS and RNS, among these are lipid peroxidation, DNA and protein damage. This may have several consequences, as follows: 1) parenchymal and endothelial cells are damaged by ROS [27], which may lead to increased vascular permeability $[28,29]$; 2) damage of surfactant-specific proteins and chemical modification by reactive radicals may markedly contribute to impaired surface activity and have indeed been observed in several studies [4]; and 3) probably even more important than direct surfactant damage, oxidant-induced disturbances in alveolar type II cell surfactant synthesis and metabolism may account for the pronounced impairment of surfactant function encountered in ARDS [8, 9, 30].

Despite a wealth of investigations, the precise modes of action of low molecular weight antioxidants in biological fluids and tissues, the relative importance of individual antioxidants, and their individual impact on total antioxidant capacity in the alveolar compartment remain poorly understood. Furthermore, the sources of antioxidants and their metabolism in the ELF are still unclear [1].

The most prominent finding of the current study, the increase in antioxidants in the alveolar compartment, may provoke the speculation that antioxidant metabolism in 
alveolar epithelial cells is accelerated under oxidative stress during ALI. However, it should be kept in mind that the currently used study design cannot further strengthen such a hypothesis, mainly because total BALF antioxidant levels only reflect net effects of different processes. Further research is necessary to investigate antioxidant metabolism in lung epithelial cells under the conditions of oxidative stress. Recent work has focused mainly on the regulation of glutathione. For example, RAHMAN et al. [31] found that both glutathione and $\gamma$-glutamylcysteine synthetase levels increase in alveolar type II cells after oxidant treatment. This may be induced by activation of redox-sensitive transcription factors, such as nuclear factor- $\kappa \mathrm{B}$ and activator protein-1, which are involved in regulation of antioxidant genes. A recent study by BLOMBERG et al. [32] showed that single alveolar antioxidant levels are rapidly restored after depletion by diesel exhaust, indicating that there are fast metabolic pathways in the lung. During tobacco-smoke exposure [33] and in patients with asthma [34], GSH was found to be increased in BALF. Furthermore, pre-exposure of animals to sublethal oxidant stress, including ozone, hypoxia and hyperoxia, resulted in increased antioxidant levels $[35,36]$ and enhanced tolerance to subsequent hyperoxic challenge [36]. Taken together, these findings may indicate the adaptive capability of the lung in the course of oxidant-induced lung injury. Another aspect that should be considered is that the mode of ventilation during ARDS may also alter antioxidant gene expression and antioxidant release. CoPLAND et al. [37] convincingly demonstrated that the mode of ventilation has a profound impact on gene expression in the lung. As compared to a nonventilated lung, they found increased levels of proinflammatory genes (e.g. interleukin-1 $\beta$ ) in bronchiolar epithelium cells by using cell picking, in situ hybridisation and macroarray techniques after high-frequency ventilation. Significant up- and downregulation of several genes were observed already after $30 \mathrm{~min}$ of high-frequency ventilation. The authors hypothesise that mechanical stretch during high-frequency ventilation alters the lung gene profile significantly, and that these gene alterations precede the lung injury. Although these authors did not present data on antioxidant genes, these results evidently demonstrate the readiness of the lung to respond to mechanical ventilation with a profound change in the gene expression pattern that may, of course, also include antioxidant genes.

Taken together, in acute respiratory distress syndrome, the current results suggest that the alveolar oxidative challenge is associated with a net increase of low molecular weight antioxidants. Future studies will have to elucidate whether this local increase in low molecular weight antioxidants is due to local production or spillover from the blood compartment. Nevertheless, the global antioxidant capacity of the epithelial lining fluid, despite the increase in single antioxidant compounds, seems unable to fully counterbalance the increased oxidative burden. Future studies may help to clarify the relative importance of single antioxidants in protecting the lung from oxidative attack.

Acknowledgements. Portions of this report have been undertaken by $\mathrm{T}$. Luboeinski in partial requirement for his medical thesis.

\section{References}

1. Kelly JF, Buhl R, Sandström T. Measurement of antioxidants, oxidants and oxidation products in bronchoalveolar lavage fluid. Eur Respir Rev 1999; 9: 93-98.

2. Putman E, van Golde LM, Haagsman HP. Toxic oxidant species and their impact on the pulmonary surfactant system. Lung 1997; 175: 75-103.

3. Lang JD, McArdle PJ, O'Reilly PJ, Matalon S. Oxidantantioxidant balance in acute lung injury. Chest 2002; 122: Suppl. 6, 314S-320S.

4. Lamb NJ, Gutteridge JM, Baker C, Evans TW, Quinlan GJ. Oxidative damage to proteins of bronchoalveolar lavage fluid in patients with acute respiratory distress syndrome: evidence for neutrophil-mediated hydroxylation, nitration, and chlorination. Crit Care Med 1999; 27: 2028 2030.

5. Bunnell E, Pacht ER. Oxidized glutathione is increased in the alveolar fluid of patients with the adult respiratory distress syndrome. Am Rev Respir Dis 1993; 148: 1174-1178.

6. Carpenter CT, Price PV, Christman BW. Exhaled breath condensate isoprostanes are elevated in patients with acute lung injury or ARDS. Chest 1998; 114: 1653-1659.

7. Messent M, Sinclair DG, Quinlan GJ, Mumby SE, Gutteridge JM, Evans TW. Pulmonary vascular permeability after cardiopulmonary bypass and its relationship to oxidative stress. Crit Care Med 1997; 25: 425-429.

8. Holm BA, Matalon S, Finkelstein JN, Notter RH. Type II pneumocyte changes during hyperoxic lung injury and recovery. J Appl Physiol 1988; 65: 2672-2678.

9. Crim C, Longmore WJ. Sublethal hydrogen peroxide inhibits alveolar type II cell surfactant phospholipid biosynthetic enzymes. Am J Physiol 1995; 268: L129-L135.

10. Gilliard N, Heldt GP, Loredo J, Redl H, Merritt TA, Spragg RG. Exposure of the hydrophobic components of porcine lung surfactant to oxidant stress alters surface tension properties. J Clin Invest 1994; 93: 2608-2615.

11. Leff J, Parsons PE, Day CE, et al. Serum antioxidants as predictors of adult respiratory distress syndrome in patients with sepsis. Lancet 1993; 341: 777-780.

12. Comhair SA, Erzurum SC. Antioxidant responses to oxidant-mediated lung diseases. Am J Physiol 2002; 283: L246-L255.

13. Pacht ER, Timerman AP, Lykens MG, Merola AJ Deficiency of alveolar fluid glutathione in patients with sepsis and the adult respiratory distress syndrome. Chest 1991; 100: 1397-1403.

14. Bernard GR, Artigas A, Brigham KL, et al. The AmericanEuropean consensus conference on ARDS. Am J Respir Crit Care Med 1994; 149: 818-824.

15. Günther A, Siebert C, Schmidt R, et al. Surfactant alterations in severe pneumonia, acute respiratory distress syndrome, and cardiogenic lung edema. Am J Respir Crit Care Med 1996; 153: 176-184.

16. Baughman RP, Rennard SI. Bronchoalveolar lavage: general approaches to correct for variability of dilution and lung permeability. Eur Respir Rev 1999; 9: 28-31.

17. Ward C, Effros RM, Walters EH. Assessment of epithelial lining fluid dilution during bronchoalveolar lavage. Eur Respir Rev 1999; 9: 32-37.

18. Tietze F. Enzymic method for quantitative determination of nanogram amounts of total and oxidized glutathione: applications to mammalian blood and other tissues. Anal Biochem 1969; 27: 502-522.

19. Catignani GL, Bieri JG. Simultaneous determination of retinol and $\alpha$-tocopherol in serum or plasma by liquid chromatography. Clin Chem 1983; 29: 708-712.

20. Iriyama K, Yoshiura M, Iwamoto T, Ozaki Y. Simultaneous determination of uric and ascorbic acid in human serum by reversed-phase high-performance liquid chromatography with electrochemical detection. Anal Biochem 1984; 141: 238-243.

21. Eder K. Gas chromatographic analysis of fatty acid methyl esters. J Chromatogr B Biomed Appl 1995; 671: 113-131.

22. Kelly JF, Mudway I, Blomberg A, Frew A, Sandström T. Altered lung antioxidant status in patients with mild asthma. Lancet 1999; 354: 482-483.

23. Riise GC, Williams A, Kjellstrom C, Schersten H, Andersson 
BA, Kelly FJ. Bronchiolitis obliterans syndrome in lung transplant recipients is associated with increased neutrophil activity and decreased antioxidant status in the lung. Eur Respir J 1998; 12: 82-88.

24. von Wichert $\mathrm{P}$, Joseph $\mathrm{K}$, Müller B, Franck WM. Bronchoalveolar lavage. Quantification of intraalveolar fluid. Am Rev Respir Dis 1993; 147: 148-152.

25. Tölle A, Kolleck I, Schlame M, Wauer R, Stevens AP, Rüstow B. Effect of hyperoxia on the composition of the alveolar surfactant and the turnover of surfactant phospholipids, cholesterol, plasmalogens and vitamin E. Biochim Biophys Acta 1997; 1346: 198-204.

26. Sindelar PJ, Guan Z, Dallner G, Ernster L. The protective role of plasmalogens in iron-induced lipid peroxidation. Free Radic Biol Med 1999; 26: 318-324.

27. Martin WJ, Gadek JE, Hunninghake GW, Crystal RG. Oxidant injury of lung parenchymal cells. J Clin Invest 1981; 68: $1277-1288$.

28. Harlan JM, Killen PD, Harker LA, Striker GE, Wright DG. Neutrophil-mediated endothelial injury in vitro mechanisms of cell detachment. J Clin Invest 1981; 68: 1394-1403.

29. Tate RM, Vanbenthuysen KM, Shasby DM, McMurtry IF, Repine JE. Oxygen-radical-mediated permeability edema and vasoconstriction in isolated perfused rabbit lungs. $\mathrm{Am}$ Rev Respir Dis 1982; 126: 802-806.

30. Guthmann F, Kolleck I, Schachtrup C, Schlame M, Spener
F, Rüstow B. Vitamin E deficiency reduces surfactant lipid biosynthesis in alveolar type II cells. Free Radic Biol Med 2003; 34: 663-673.

31. Rahman I, Bel A, Mulier B, Donaldson K, MacNee W. Differential regulation of glutathione by oxidants and dexamethasone in alveolar epithelial cells. Am J Physiol 1998; 275: L80-L86.

32. Blomberg A, Sainsbury C, Rudell B, et al. Nasal cavity lining fluid ascorbic acid concentration increases in healthy human volunteers following short term exposure to diesel exhaust. Free Radic Res 1998; 28: 59-67.

33. Cantin AM, North SL, Hubbard RC, Crystal RG. Normal alveolar epithelial lining fluid contains high levels of glutathione. J Appl Physiol 1987; 63: 152-157.

34. Smith LJ, Houston M, Anderson J. Increased levels of glutathione in bronchoalveolar lavage fluid from patients with asthma. Am Rev Respir Dis 1993; 147: 1461-1464.

35. Kodavanti UP, Costa DL, Dreher KL, Crissman K, Hatch GE. Ozone-induced tissue injury and changes in antioxidant homeostasis in normal and ascorbate-deficient guinea pigs. Biochem Pharmacol 1995; 17: 243-251.

36. Jackson RM, Frank L. Ozone-induced tolerance to hyperoxia in rats. Am Rev Respir Dis 1984; 129: 425-429.

37. Copland IB, Kavanagh BP, Engelberts D, McKerlie C, Belik J, Post M. Early changes in lung gene expression due to high tidal volume. Am J Respir Crit Care Med 2003; 168: 1051-1059. 